\title{
Role of higher education in sustainable development of regions
}

\author{
Zhanna Gardanova ${ }^{1}{ }^{*}$, Natalya Nikitina $^{2}$, Veronika Grebennikova $^{3}$, and Vyacheslav Ilgov ${ }^{1}$ \\ ${ }^{1}$ Department of Psychotherapy, Pirogov Russian National Research Medical University, \\ Ostrovityanova str. 1, Moscow, 117997, Russian Federation \\ ${ }^{2}$ Research Institute for Advanced Directions and Technologies, Russian State Social University, 4 \\ Wilhelm Pieck str., bld. 1, 129226 Moscow, Russian Federation \\ ${ }^{3}$ Faculty of Pedagogy, Psychology and Communication, Kuban State University, Stavropol str. 149, \\ 350040, Krasnodar, Russian Federation
}

\begin{abstract}
The role of higher educational institutions (HEIs) in sustainable regional development is becoming a subject of attention of researchers and policymakers. Apart from clear inputs such as sustainable education and promotion of renewable energy sources, HEIs can act as partners and consultancies for the local authorities helping them to embark on the path of sustainable economic and social growth. Our paper looks into the role of higher education in sustainable development of regions. We identify HEIs as the hubs of knowledge and know-how spill-overs as well as active players in industry-university connection. Our results confirm the importance of higher education in promoting the decarbonization of economy, helping the transition to the renewables and the creation of wider social acceptance of sustainable development.
\end{abstract}

\section{Introduction}

There are many environmental problems cannot be understood by isolating them from the political and economic context in which they arise, even if they create situations of environmental injustice [1]. Resources with ecological sustainability are usually identified and characterized by their role in the socio-economic and social conditions of the environment. The development capacity of the territory is based on the different development and use of the land, taking into account the potential of different types of use (e.g. development, type of use and type of use) and assessing the appropriateness of their use [2]. This can provide for scientific planning of development use and identify problems and risks of current use, so that high-quality development can be promoted. Relative sustainability is assessed in order to promote the relative degree of use of resources in relation to their ecological sustainability, thereby promoting the harmonious development of man and nature. Natural resource development is governed by a complex regulatory system that includes land claims, land-use planning, and land management policies. A comprehensive land claim agreement contributes to environmental protection by setting out the environmental and cultural importance of the land for the community and initiating a land use and planning

*Corresponding author: zanna7777@inbox.ru 
process [3]. The protection of this environment is important for the inhabitants who depend on water and land for their livelihood and economic development. Much of the land occupied by indigenous peoples is in ordinary ownership, but only a fraction of that land is recognized by many governments as formally and legally indigenous. There are precarious land rights, and even if indigenous territories and lands are recognized, external parties and their ability to exploit natural resources is weak. This threatens cultural survival and vital knowledge systems that contribute to the biodiversity and environmental health on which we all depend. Promoting the protection and promotion of the rights of peoples on their land and territory and the development of sustainable livelihoods and economic opportunities for their communities - it is to promote the development of mechanisms to prevent the exploitation and exploitation of biodiversity for commercial and industrial purposes and to protect the rights of indigenous peoples on their land and territory $[4,5]$. Integrating the principles of sustainable development and livelihoods and economic opportunities for peoples into the framework of international law. This might help to develop a better understanding of how the relationships between society, nature, territory and governance play out.

In order to help the sustainable development of regions, one needs to learn how to assess environmental impacts in terms of the social, economic, social and political conditions of the territory and its governance [6]. For example, in Canada there is the Environmental Assessment Act (CEAA) which applies to certain other state-regulated areas, including offshore waters. Canada's three territories are northern communities that need long-term economic growth [7]. Based on a unique co-management approach based on the principles of sustainable development, environmental responsibility and the sustainable management of natural resources. Such a global analysis is then complemented by a local value chain that takes into account social and economic indicators developed at the local level. United Nations Habitat and UNIDO have combined their efforts and expertise into a methodology that not only explains the industrial performance of strategic sectors, but also takes into account the social, environmental and social conditions of the areas and their communities [8]. By bringing together global and local assessments in a single framework, the initiative aims to boost industrial growth in Mexico by developing territorial approaches to properly meet and achieve the United Nations Sustainable Development Goals (SDGs). Modern tactics of territorialization usually aim to recognize local territoriality, to include it in the discourse, to discipline it, and to integrate local norms, practices, and discourses into the mainstream. As a participatory strategy, it makes use of a managed neoliberal multiculturalism and recognizes the need to integrate and marginalize locally existing territories. Such methods also allow specific characteristics to be identified which, by virtue of their specific characteristics, could be included in the production phase by the different regions and municipalities of a country and their countries.

\section{Difference in regional development across regions}

Regional development has many interesting implications. For example, GDP per capita of the European Union New Member States (i.e. those that joined the EU in 2004) has increased and that these countries are therefore catching up with the older EU countries (EU15) in this area [9]. Moreover, the European Commission's Economic and Social Research Office beta convergence analysis suggests that there is a narrowing gap between the CEE countries and the rest of European Union [10]. At the same time, some studies show that the performance of the CEE countries in this area is consistent with that of the rest of Europe in terms of GDP per capita. Regions with high absorption of EU funds also show a correlation with development indicators, as observed in the performance of knowledge and innovation potential. On the other hand, the region with the highest borrowing by the European Union shows a negative correlation between development performance and the level of investment 
in research and development [11]. Knowledge, innovation and potential performance is also higher in the CEE than in other regions of Europe. This can also be used to make comparisons with fast-growing emerging markets and oil-producing countries such as the Middle East and Africa (MENA countries). Various indicators are used to show which countries have the highest current levels of development and which have made the most progress recently. One also needs to assess whether a country is capable of translating the current level of development and recent progress into the well-being of its population. Finally, one needs to take a look at the dimensions of socio-economic development that distinguish themselves from the leading countries [12]. Recent progress is measured as a measure of how much a country for which data is available has achieved in the past decade. Long-term sustainability is assessed as a factor that helps to continue improvements in each of the ten dimensions of socio-economic development into the next generation.

One can measure the impact of socio-economic development on the well-being of the population, measured by the number of people who have access to health, education, housing and other basic needs. A coefficient greater than 1 indicates that a nation's standard of living is higher than one would expect from a given nation with a GDP, while a coefficient smaller than -1 indicates that it is closer to what one would expect from a giving nation without a GDP [13]. The concept of path dependence is also used to describe regional economic development paths, taking into account historical economic and political legacies. Moreover, a dependent process that is believed to shape regional innovation systems in what is now considered a place can then be based on a development model. Although urbanization does not necessarily lead to economic development, other factors can play an important role in boosting economic growth and raising living standards. For example, the presence of builtup areas such as parks, schools, hospitals, and other public facilities associated with urbanization can help to stimulate economic growth and development. Recent cross-border evidence also shows that the potential of urbanization to foster growth probably depends on the ability to remove barriers to growth, such as lack of access to affordable housing and public transport. This relative pattern does not, however, alter the fact that developing countries have higher levels of urbanization than developing countries [14]. To explain the differences between countries, other factors must be considered that summarize how nations differ in terms of economic growth and living standards, and in levels of poverty and inequality. Moreover, the share of urban populations in countries worldwide exceeded $10 \%$ in 2011, and those with higher urbanization in this group have higher per capita GDP. Developing countries face a dilemma: they have no choice but to implement accelerated urbanization to catch up with their neighbours in terms of economic growth and living standards, but they also have their own challenges in achieving these goals.

\section{Triple Helix strategy in regional development}

Applying governance innovations to stakeholder-based city systems is a relatively new interdisciplinary line of thought that goes beyond the institutional relationships and aims to provide governance's guidance information to address the complexity of a wide range of organisations, with a focus on interaction between governance, governance systems, institutional structures and governance models $[15,16]$. The Triple Helix model draws attention to the role of governance innovation in the development the systems [17]. The contributions of this research aim at assessing the impacts of a range of topics, including governance, governance systems, institutional structures and governance models. In general, it stems out that the central element in the production of knowledge and innovation is considered to be an irreplaceable source of knowledge for human survival. The Smart Specialisation Strategy, to which Smart Growth Europe contributes, introduced by the European Commission's Office for Science, Technology and Innovation (ETSI) and the 
European Union (EU), has highlighted that the innovation process is increasingly seen as an open system in which different actors work and interact [18].

Environmental and biodiversity protection promote knowledge and innovation towards a sustainable social economy in which all actors are responsible for developing sustainable, sustainable and sustainable solutions to the challenges of the future. This will be essential to promote long-term innovative strategies [19]. This paradigm shift, which directly involves the formulation of strategies for end-user innovation, is changing the role of actors in the innovation process. This has changed the roles of all actors in the innovation process and, according to the hypothesis of this model, the development of an innovation strategy requires the participation of civil society in the planning process through a hypothetical model (see Figure 1).

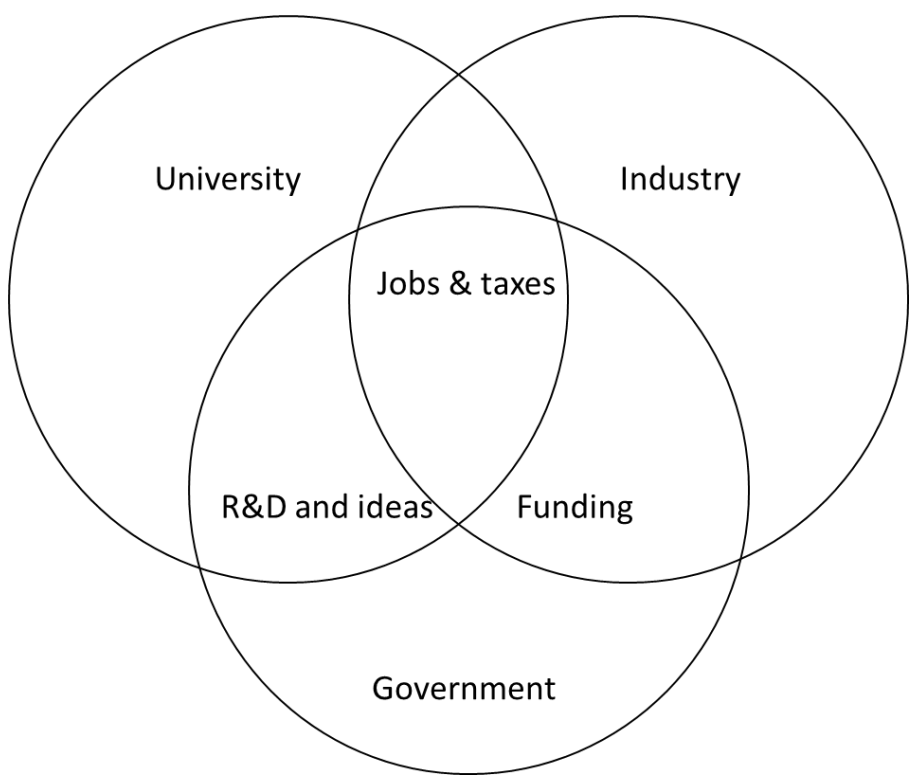

Fig. 1. Triple Helix model of innovation between universities, government, and industry

Figure 1 explains how the universities provides research and development as well as ideas that can be implemented into practice. The government provides the funding that helps the universities to function and for the ideas to be implemented into real life. The industry provides jobs and pays taxes that accumulate the budgets of the governments and the whole cycle goes over and over again. Further steps can be taken with the Triple Helix model that helps to implement this innovation model in rural areas. The last, but not the last, contribution opens up the possibility of elevating this concept and illustrates the role of civil society in the development of a multi-helix strategy for rural development. Using data-driven analysis, some researchers conducted a series of interviews with local leaders and entrepreneurs [20, 21]. The focus was on governance and network orchestration within and outside the metropolitan region. The European programme reopens the debate on the old link between innovation and territory by targeting the technology of regional and urban innovation systems. This requires an integrated understanding of network orchestration, governance and governance systems within and outside the metropolitan region. The so-called Smart City, which is still a blurred concept, is being developed within inclusive approach that consists of high technology [22]. In the transition from an industrial innovation economy, strategic management as a method of university management is a new area of research in this changing 
environment. The following collection of papers summarizes the results of a series of studies in the field of strategic planning of territorial development. It has been shown that the main problem is when universities, business and government actively interact. Such an approach should be based on a consensual - long-term - strategy for territorial development. Moreover, such a strategic alliance includes a strategy aimed at developing and exploiting resources in specific characteristics of the region. To this end, industry must be supported and fully supported in development, and governments can help to organise the development of the economy, infrastructure, education, health and social services and other sectors. So far, we have seen that centralisation of research and finance, with the state acting as a levy-generating authority, has roughly explained Australia's export success. However, it was a success that Triple Helix coordination was able to prevail through common consensus and common longterm strategies. The importance of decentralised coordination in the development of the TriHelix strategy and its implications for the future of regions remains a very relevant issue. A panel on Triple Helix best practices presented a number of published Triple Helix sector cases that show that the company-led Triple Helix constellation is an emerging practice. With this understanding, civil society is able to demand and take a more active role in the development and implementation of the Tri-Helix strategy. Further details on the cases can be presented, highlighting the importance of decentralised coordination and the role of public-private partnerships in this process, as well as the need for greater transparency. Entrepreneurship broadens this broader vision by mapping the role of entrepreneurship in regional development and its impact on the global economy and society.

\section{Role of HEls in regional development}

Higher education institutions must also take the lead in developing and implementing regional economic plans that take into account the needs of the local economy, particularly in the areas of cluster development and economic development [23, 24]. Universities influence economic growth because they are buyers of goods and services from the region. Data on the number of universities and their growth rates can be used to analyse the impact of university growth on regional economic development and growth in the regions. It turns out that the expansion of higher education during that period was not only a product of the rich, but also helped to spur economic growth around the world. We believe that there is a strong correlation between the number of universities and the rate of economic development in the region [25]. The value of an institution and its environment is limited if it contributes only to the level of economic activity, but even if it contributes to economic growth in the region, it is limited. This could be a good reason for governments to spend limited resources on establishing or subsidizing local universities and colleges. However, a careful assessment of the scale and scope of these benefits is essential to allow a better understanding of these investments and the high cost of such investments.

As societies increasingly become drawn into the maelstrom of globalization, virtually all higher education systems in the world are forced to limit the scope of their activities. These activities range from the creation of impressive science and technology parks with the aim of establishing closer links with industry, to the establishment of new universities and colleges with a focus on science, technology, engineering and mathematics. As the epitome of the knowledge institutes of modernity, universities are at the forefront of this development and have been identified as a fundamental pillar of the competitiveness of nations and regions.

Despite renewed attention to this issue, little scientific attention has been paid to the roles played by universities in relatively remote regions in their local environment. This knowledge gap needs to be addressed by comparing a number of cases of institutions in each region with their role in knowledge development - intensive goods and services in different regions [26]. It is crucial to examine the role of highly educated individuals in the development of 
knowledge - intensive goods and services in different regions. In times of global crises, it can be observed that it is necessary to propose sustainable solutions to human development, as this concerns adequate access to education, health care, social services and other basic human needs. Another key objective would be to examine best practices in this area in relation to the use of higher education as a tool for development and the implementation of sustainable development.

In addition, we need to understand how regional innovation strategies can be developed to achieve the highest level of competitiveness in the context of a region's economic development and growth. This approach to regional development understands the need to develop an entrepreneurial attitude in the process of creation in order to manage regional growth. Before discussing the role of entrepreneurial universities in leading regional skills development strategies, we must point out that today the impression of the entrepreneurial university as a strategic initiative is gradually being recognised as an important part of innovation and regional growth networks for entrepreneurial growth. Nevertheless, there are efforts to protect certain loopholes in regional innovation systems, given the strategic role of entrepreneurial colleges and universities. Therefore, the entrepreneurial activities of universities can be provisionally identified as their main activities for the development of knowledge - based societies and competitiveness, as well as entrepreneurial contexts, including innovation networks. In the context of the regional strategy, the creative development process of the region must have a global charisma, where its application is regional and its application regional. In order to make it more relevant to the development of the regional economy, it is necessary to link the regional level with the national level and, in particular, with the global level. Although the study is understood within a limited time frame, the paper discusses an effective approach to regional entrepreneurial activities that creates awareness and innovation and has economic value for the province. Therefore, on the basis of the above-mentioned discussion and understanding, it is imperative to mention that the region must develop its territorial knowledge and growth, which fosters an innovative attitude to leadership and governance, i.e., promote industrial competitiveness. We therefore can observe that the potential of a region to apply knowledge can be harnessed when the efficiency of the regional innovation ecosystem is determined by effective cooperation and policy approaches. Improving entrepreneurial innovation and attracting the entrepreneurial spirit of this ecosystem will improve knowledge production in the regions. It can therefore be said that the entrepreneurial universities and their strategic initiatives can play a crucial role in promoting the entrepreneurial spirit of the region by providing the necessary guidance and services in a rational manner. The entrepreneurial education process and approach will enable people not only to learn about entrepreneurship, but also to develop the skills needed to guide the growth of new entrepreneurial ventures. There are the initiatives being discussed by the business universities and the important role that regional innovation strategies can play in strengthening innovation-driven regional economic growth. To address the fundamental characteristics of the region's entrepreneurial culture and its role in regional development, it is necessary to highlight the emerging perception that there is a reason for change - a new mindset and approach to entrepreneurship development. The emerging concept of the Entrepreneurship University creates regional advantages not only in terms of economic growth, but also in terms of developing entrepreneurial skills and qualifications [27]. In the age of modernisation, innovation has been observed to lead to regional growth and networks for entrepreneurship, and regions are born of knowledge - innovation linked to regional development strategies. To meet the need for innovation, aby region's oriented regional university for growth and entrepreneurship needs to look at the role of universities in regional economic development and innovation development. Where the preliminary description refers to the following guidelines, which can be considered stepping stones for the innovation-led region - growth building and the business network. On the basis of the above- 
mentioned discussion, it is crucial to stress that the deliberate activities of entrepreneurial universities affect regional economic development. Where we expect the region's strategic successes to enable it to face undesirable challenges and prepare to move into a better position in the global market for innovation and innovation, led by regional growth.

Overall, it is clear that high-performing regions have organised themselves to support innovation, entrepreneurship and sustainable development, and the impact this has on their surrounding business communities. The places people have studied that are doing well appear to be doing so through an integrated approach to economic development that takes into account the role of entrepreneurial universities in the development of their economies.

\section{Conclusions}

The aim of this paper was to assess and differentiate the impact of different types of institutions on regional and global economies with respect to their sustainable development and growth. We showed that higher educational institutions (HEIs) are playing an increasingly important share in sustainable regional development. HEIs can act as partners and consultancies for the local authorities helping them to follow the path of sustainable economic and social growth. It appears that HEIs can be identified as the hubs of knowledge and know-how spill-overs as well as active players in industry-university connection. We find that higher education can also be extremely helpful in promoting the decarbonization of economy, helping the transition to the renewables and the creation of wider social acceptance of sustainable development.

With regard to our findings, one can note a growing interest in contributing to the United Nations Sustainable Development Goals (SDGs) by training students at HEIs all around the world. Through an ongoing review of higher education trends, one can exploring how leading higher education institutions can contribute to much-needed social change beyond their classrooms. Some further research can be useful to explore how leading universities and institutions can contribute to social and economic development.

\section{References}

1. S. Banzhaf, L. Ma, C. Timmins, Journal of Economic Perspectives, 33(1), 185-208 (2019)

2. H. Dkhili, Marketing and Management of Innovations, 3, 333-344 (2018)

3. A. Dale, K. Vella, S. Ryan, K. Broderick, R. Hill, R. Potts, T. Brewer, Land, 9(7), 234 (2020)

4. G. Magni, European Journal of Education, 52(4), 437-447 (2017)

5. B. Chen, Z. Qiu, N. Usio, K. Nakamura, Sustainability, 10(8), 2896 (2018)

6. O. Voronkova, V. Yankovskaya, I. Kovaleva, I. Epishkin, I, Iusupova, Y. Berdova, Entrepreneurship and Sustainability Issues, 7(1), 662-673 (2019)

7. L. McCallum, C. Ollson, I. Stefanovic, Impact Assessment and Project Appraisal, 36(1), 5-15 (2018)

8. M. Naidoo, A. Gasparatos, Journal of Cleaner Production, 203, 125-142 (2018)

9. W. Strielkowski, F. Höschle, Technological and Economic Development of Economy, 22(4), 617-630 (2016)

10. M. Borsi, N. Metiu, Empirical Economics, 48(2), 657-681 (2015)

11. S. Anton, A. Nucu, Renewable Energy, 147, 330-338 (2020)

12. B. Moldan, S. Janousková, T, Hak, Ecological Indicators, 17, 4-13 (2012)

13. Y. Bilan, H. Mishchuk, I. Roshchyk, I. Kmecova, Journal of Competitiveness, 12(1), $22-$ 38 (2020) 
14. Y. Ji, X. Guo, S. Zhong, L. Wu, Land, 9(12), 481 (2020)

15. T. Clauss, A. Moussa, T. Kesting, International Journal of Technology management, 77(1-3), 109-144 (2018)

16. J. Abrham, W. Strielkowski, M. Vošta, J. Šlajs, Agricultural Economics, 61(10), 450 (2015)

17. M. Scalia, S. Barile, M. Saviano, F. Farioli, Sustainability Science, 13(5), 1235-1244 (2018)

18. P. Palos-Sanchez, Harvard Deusto Business Research, 6(2), 116-132 (2017)

19. W. Leal Filho, S. Tripathi, J. Andrade Guerra, R. Giné-Garriga, V. Orlovic Lovren, J. Willats, International Journal of Sustainable Development \& World Ecology, 26(2), 179190 (2019)

20. W. Strielkowski, M. Krejcí, I. Čabelková, Business: Theory and Practice 16(3), 304-315 (2015)

21. R. Purbasari, C. Wijaya, N. Rahayu, Review of Integrative Business and Economics Research, 9, 157-175 (2020)

22. S. Edge, K. Boluk, M. Groulx, M. Quick, Cities, 96, 102478 (2020)

23. M. Dvorak, P. Rovny, V. Grebennikova, M. Faminskaya, Terra Economicus, 18(4), 78 $96(2020)$

24. Z. Gardanova, V. Ponkratov, N. Kuznetsov, N. Nikitina, O. Dudnik, E. Latypova, S. Shcherbatykh, Journal of Open Innovation: Technology, Market, and Complexity, 6(4), 1-21 (2020)

25. A. Valero, J. Van Reenen, Economics of Education Review, 68, 53-67 (2019)

26. A. Beer, S. Ayres, T. Clower, F. Faller, A. Sancino, M. Sotarauta, Regional Studies, 53(2), 171-182 (2019)

27. M. Klofsten, A. Fayolle, M. Guerrero, S. Mian, D. Urbano, M. Wright, Technological Forecasting and Social Change, 141, 149-158 (2019) 